\title{
Seasonal changes in the in-vivo activity of the luteinizing hormone-releasing hormone (LHRH) neural apparatus of male rabbits monitored with push-pull cannulae
}

\author{
W. W. Lin and V. D. Ramirez \\ Department of Physiology and Biophysics, 524 Burrill Hall, University of Illinois, \\ 407 South Goodwin Avenue, Urbana, Illinois 61801, USA
}

\begin{abstract}
Summary. Intact sexually mature New Zealand White male rabbits, raised under natural lighting and temperature conditions, were isolated and housed in airconditioned quarters, in a 12-h light:12-h dark cycle. Push-pull cannulae were implanted towards the tuberal region of the hypothalamus, and animals were perfused with modified Krebs'-Ringer phosphate medium for an average period of $4 \mathrm{~h}$. Most rabbits were repetitively perfused over an average period of $3 \cdot 7$ months. Perfusions were grouped into seasonal periods of about 40 or 80 days through the entire 1-year cycle: (A) 23 November to 31 December (winter solstice period: $N=6$ ), (B) 1 January to 23 March (winter: $N=10$ ), (C) 24 March to 13 June (spring: $N=9$ ), (D) 14 June to 23 July (summer solstice period: $N=23$ ), (E) 24 July to 13 October (late summer-early fall: $N=7$ ) and (F) 14 October to 22 November (fall: $N=4$ ). Maximal and minimal values of mean release, mean amplitude and mean frequency from every animal in each block were obtained. In the summer solstice group (D), maximal mean ( \pm s.e.) LHRH release levels were significantly greater $(14.42 \pm 6.62 \mathrm{pg} / 10 \mathrm{~min})$ than for all groups $(A$, $0.76 \pm 0.27 ; \mathrm{B}, 1.59 \pm 0.39 ; \mathrm{C}, 1.34 \pm 0.22 ; \mathrm{E}, \mathrm{l} \cdot 33 \pm 0.33$; and $\mathrm{F}, 1 \cdot 18 \pm 0.11$ ) while during the winter solstice period (A), minimal mean LHRH release levels $(0.48 \pm 0.04 \mathrm{pg} / 10 \mathrm{~min})$ were significantly lower than in all other groups (B, $1.43 \pm 0.41 ; \mathrm{C}, 0.96 \pm 0 \cdot 11 ; \mathrm{D}, 7 \cdot 25 \pm 4 \cdot 12 ; \mathrm{E}, 1 \cdot 18 \pm 0.37 ;$ and $\mathrm{F}, 1 \cdot 18 \pm 0 \cdot 11)$ Maximal values were highest during the summer solstice period while the mininal values were lowest during the winter solstice period. The amplitude and frequency of the LHRH pulses showed changes similar to those observed with the mean LHRH release. For 1 year, an estimated left testis weight was measured in 4-7 rabbits every 2-5 weeks. The percentage estimated testis weight peaked in early August and reached minimal levels during the winter months. These data demonstrate that the rabbit LHRH neural apparatus is very sensitive to seasonal influences although animals remained in a fixed photoperiod during the entire duration of the experiment.
\end{abstract}

Keywords: LHRH; push-pull cannulae; circannual rhythms; rabbit

\section{Introduction}

Wild rabbits have a seasonal cycle of reproduction characterized in males by significant changes in testicular size and testosterone, luteinizing hormone ( $\mathrm{LH})$ and follicle-stimulating hormone (FSH) concentrations (Elder \& Finerty, 1943; Davis \& Meyer, 1973; Lincoln, 1976; Boyd \& Myhill, 1987). Gonadotrophin concentrations increase with testicular weight during the spring and summer months and decline during the fall, reaching minimal levels during the winter solstice. Some studies have indicated that these seasonal changes in testicular weight as well as in fecundity are not eliminated in domestic rabbits housed under conditions of constant light:dark cycles (Carson \& Amann, 
1972; Reed, 1979). In an attempt to study some of these hormonal and environmental factors which are involved in circannual hypothalamic-pituitary-gonadal axis rhythms of the rabbit, we have studied seasonal changes in LHRH release by using a push-pull cannula to monitor changes in LHRH release in vivo in freely behaving rabbits (Lin \& Ramirez, 1988/90).

\section{Materials and Methods}

Animals. Sexually mature male New Zealand White rabbits $(N=19)$, raised under natural lighting conditions and exposed to seasonal variation in light duration and changes in temperature $\left(5^{\circ} \mathrm{C}\right.$ in winter to $26^{\circ} \mathrm{C}$ in summer), were obtained from a local supplier (Johnson, Wilkenson, IN, USA). On arrival, rabbits were isolated and housed in airconditioned quarters, under a 12-h light:12-h dark cycle (lights on at 06:00 h). All rabbits were provided with water and rabbit food pellets ad libitum as well as supplements of fresh lettuce. At least 1 week was allowed to accustom the rabbits to their new quarters before surgery.

Implantation of the cannula. Rabbits $(3.45 \pm 0.10 \mathrm{~kg} ; N=18$; the weight record from 1 rabbit was missing) were implanted with a push-pull cannula as previously described (Lin \& Ramirez, 1988). On the day of implantation, animals were weighed and anaesthetized with a mixture of ketamine-acepromazine $(60 \mathrm{mg} / \mathrm{kg} ; 1: 1 \mathrm{ratio}$, i.m.). Approximately 15-20 min later, the rabbit's head was positioned into a rabbit head holder. Construction (Dluzen \& Ramirez, 1986) and implantation (Lin \& Ramirez, 1988) of the cannula were as described previously. The cannula was aimed towards the medial basal region of the hypothalamus using the following stereotaxic co-ordinates derived from the Rabbit Brain Atlas of Sawyer et al. (1954): $1 \mathrm{~mm}$ posterior from the bregma, $1 \mathrm{~mm}$ lateral from the midline and $16.5 \mathrm{~mm}$ vertical from the calvarium. The cannula assembly was connected with polyethylene tubing (PE-20, Clay Adam's Co., Parsipany, NJ, USA) to 2 separate peristaltic pumps (Rabbit miniature peristaltic pumps, Rainin Instrument Corp., Woburn, MA, USA), one to push medium through the perfusion system and the other to pull medium at exactly the same flow rate $(10-14 \mu \mathrm{l} / \mathrm{min}$, with most of the perfusions at around $12 \mu \mathrm{l} / \mathrm{min})$.

Push-pull perfusion experiments. On the day of perfusion, the animal was brought to the laboratory at about 10:00 $\mathrm{h}$. The rabbit was placed in an open-top metal cage $(51.0 \times 45.5 \times 40.5 \mathrm{~cm})$ with holes in the walls for air circulation. Within this cage, the animal was free to move, dig, eat, drink and rest. Peristaltic pumps were adjusted to achieve a balanced flow rate between the push and pull cannulae while the animal adjusted to the new environment, usually taking about $1-2 \mathrm{~h}$. Filtered (Millipore Filter- $45 \mu \mathrm{m}$ ) modified Krebs'-Ringer phosphate (KRP) medium, which consisted of $123 \mathrm{mM}-\mathrm{NaCl}, 4.8 \mathrm{mM}-\mathrm{KCl}, 0.27 \mathrm{mM}-\mathrm{CaCl}_{2}, 1.2 \mathrm{mM}-\mathrm{MgSO}_{4}$ and $12 \mathrm{~mm}$-sodium phosphate buffer, $\mathrm{pH} 7 \cdot 4$, was used to perfuse the hypothalamic area of these rabbits.

Experimental design. Altogether 19 male rabbits were subjected to 59 perfusion experiments with modified KRP medium for an average period of $4 \mathrm{~h}$. Push-pull perfusate samples were collected every $10 \mathrm{~min}$ into tubes on ice, acidified with $1 \mathrm{~N}-\mathrm{HCl}$ to a final concentration of $0.1 \mathrm{~N}$ and frozen until LHRH measurements were performed by RIA, as previously reported (Hartter \& Ramirez, 1985). The intra-assay coefficient of variation in these assays at a dose of $1.0 \mathrm{pg} \mathrm{LHRH} /$ tube was $4.9 \%$. The interassay coefficient of variation was $5.7 \%$ at the 5 -pg dose. The sensitivity of these assays was typically $0.5 \mathrm{pg}$ at $95 \%$ bound. The data from individual rabbits were analysed by the Pulsar program (Merriam \& Wachter, 1982) for detection of pulses and mean output using a $10 \%$ error for the calculation of the $\mathrm{G}$ values according to a normal distribution probability. The Pulsar program was adapted for an IBM-PC microcomputer in our laboratory by J. Gitzen (Gitzen \& Ramirez, 1987). Perfusions were grouped into seasonal periods of about 40 or 80 days through the entire 1 year cycle, i.e. (A) 23 November to 31 December (winter solstice period: $N=6$ ), (B) 1 January to 23 March (winter: $N=10$ ), (C) 24 March to 13 June (spring: $N=9$ ), (D) 14 June to 23 July (summer solstice period: $N=23$ ), (E) 24 July to 13 October (late summer-early fall: $N=7$ ) and (F) 14 October to 22 November (fall: $N=4$ ). The effects of seasonal changes on the function of the LHRH neural apparatus were analysed by obtaining the maximal and minimal values of mean release, mean amplitude and mean frequency from every animal in each period. For example, if an animal was perfused 4 times during the summer solstice period, the maximal and minimal values would be obtained from the 4 experiments. A Kruskal-Wallis one-way analysis of variance followed the Mann-Whitney $U$ test were performed on these data, and an $\alpha$ value of $\leqslant 0.05$ was required for results to be considered statistically significant. This analysis was included to take into consideration the relatively narrow window when the activity of the LHRH neural apparatus reaches maximal or minimal activity. By using only a mean value for the entire block, the extreme values detected in the summer solstice (highest activity) and in the winter solstice (lowest activity) are obscured by the other values in the average. Therefore, an analysis using the maximal or minimal values is a more appropriate method to analyse the data. However, the mean release, mean amplitude and mean frequency of LHRH pulses for all the experiments corresponding to each block were also computed.

Brain histology. Animals were anaesthetized using ketamine-acepromazine $(60 \mathrm{mg} / \mathrm{kg} ; 1: 1 \mathrm{ratio})$ followed by ether. They were then perfused from the heart with saline, followed by formaldehyde-saline, and histological analyses were performed on brain slices as described previously (Ramirez et al., 1986).

Testis measurements. For 10 rabbits, 9 of which were also perfused (see above), the left testicular length and width were measured every 2-5 weeks between 24 January 1989 and 10 January 1990 . In addition, the weight of each rabbit 
was recorded. An index of testicular weight $(\mathrm{I})$, derived from the length $(\mathrm{L})$ and width $(\mathrm{W})$ measurements and given by $\mathrm{I}=\log \left(\pi(\mathrm{W} / 2)^{2} \mathrm{~L}\right.$ ) was calculated (Boyd, 1986a). This index of testicular weight has been shown to provide a good approximation of true testicular weight $(r=0.96)$ (Boyd, 1986a). The estimated testicular weight was then calculated from the following formula:

$$
\text { estimated weight }=(I+0 \cdot 2336) / 0 \cdot 2997
$$

The \% estimated weight/body weight was analysed using one-way analysis of variance followed by the Least Significance Difference Test, and an $\alpha$ value of $\leqslant 0.05$ was required for results to be considered statistically significant.

\section{Results}

\section{General comments}

Many of the rabbits were perfused more than once without any detrimental effects. In addition, 3 of the bucks in this study were perfused repeatedly over a period of 1 year. During perfusions, animals were calm, resting or sleeping, but remained responsive to any ambient noise in the laboratory. They exhibited normal behaviour, such as standing and lying with periods of hopping, turning, eating, drinking and rearing.

\section{Brain histology}

The cannula placements in these animals ranged as posterior as the mamillary bodies and as anterior as the ventral medial nucleus. Most of the perfusion sites were at the ventral or dorsal medial nuclei.

\section{LHRH changes over the season}

The profiles of 4 individual rabbits repeatedly perfused during different seasons are shown in Figs 1-4. Figure 1 illustrates marked changes in the activity of the LHRH neural apparatus in Rabbit 40, which was transferred to the control photoperiod on 11 June 1986 and subsequently perfused from 21 June 1986 to 7 July 1987. Panel A shows the profile of the first perfusion on 21 June 1986, on the first summer solstice, with a mean LHRH release rate of $3.07 \mathrm{pg} / 10 \mathrm{~min}$. The second perfusion, at the end of the winter of 1987 on 15 March 1987 (Panel B), revealed a mean LHRH release rate of $1.20 \mathrm{pg} / 10 \mathrm{~min}$ while the mean LHRH release rate of the third perfusion (Panel C), immediately before the second summer solstice (16 June 1987 ), was $0.95 \mathrm{pg} / 10 \mathrm{~min}$. The fourth perfusion, 2 days after the second summer solstice, showed a 2 -fold increase in the mean LHRH release rate $(1.95 \mathrm{pg} / 10 \mathrm{~min})$ with marked increases in the amplitude of LHRH pulses. The fifth perfusion (Panel E) took place on 7 July 1987, and the mean LHRH release rate rose to $37.50 \mathrm{pg} / 10 \mathrm{~min}$ with maximum amplitude of pulses at $100 \mathrm{pg}$. These marked changes in LHRH release occurred while the buck remained in a constant photoperiod for over a 1-year period. Similar seasonal changes were seen in Rabbit 39 shown in Fig. 2. Rabbit 39 was transferred to the constant photoperiod on 14 May 1986 and was subsequently perfused 3 times from 23 June 1986 to 13 February 1987. The first perfusion, shown in Panel A (about 5 weeks after arrival and 2 days after the summer solstice), revealed very high mean LHRH levels $(36.56 \mathrm{pg} / 10 \mathrm{~min})$ with maximum amplitude of pulses at $100 \mathrm{pg}$ (notice the change in scale of the $y$ axis). Such high levels of LHRH release have so far only been observed in male rabbits perfused near the summer solstice and have never been observed under other experimental conditions. In addition, these very high levels were independent of the number of prior perfusions, as demonstrated in Rabbit 39 which showed high levels during the first perfusion, unlike Rabbit 40 which showed high levels only during the fifth perfusion. In the second perfusion, 1 month later (Panel B), LHRH values decreased dramatically to $2.62 \mathrm{pg} / 10 \mathrm{~min}$ while in the last perfusion (Panel C), during the winter of 1987 , mean LHRH release levels were only $0.88 \mathrm{pg} / 10 \mathrm{~min}$. Figures 3 and 4 illustrate similar seasonal changes in the activity of the LHRH neural apparatus in Rabbits 137 and 138, both of which had been transferred to a constant photoperiod on 1 March 1989. In contrast to Rabbits 40 and 39, Rabbits 137 and 138 

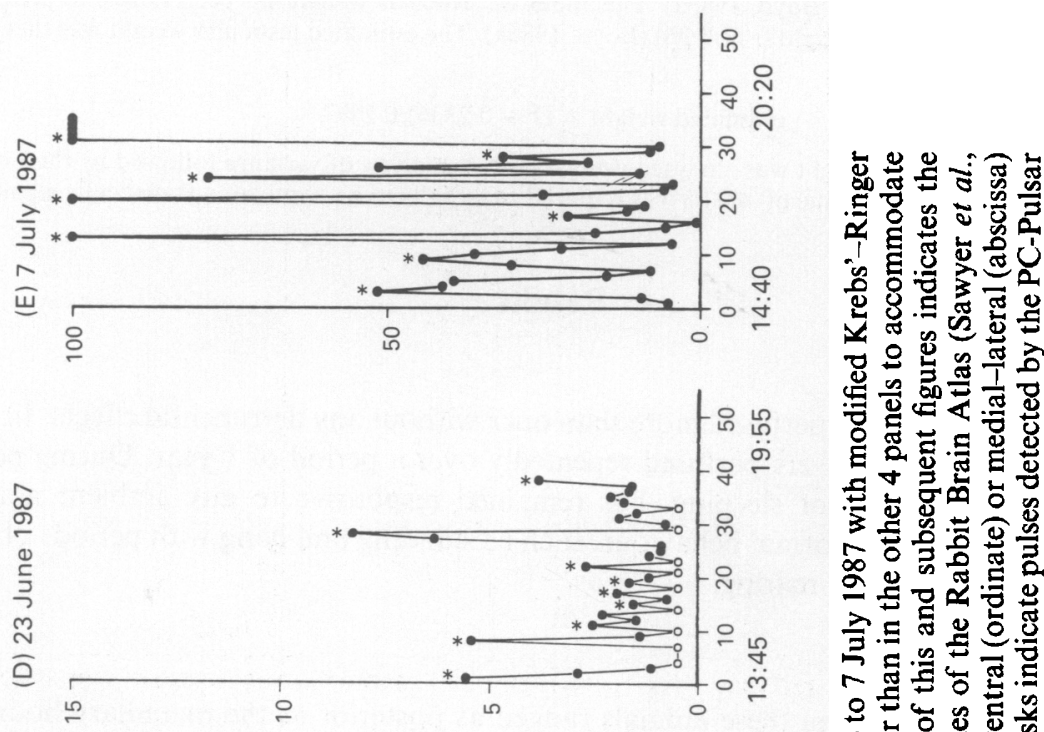

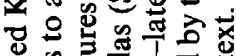

象总要焉志

蛋.

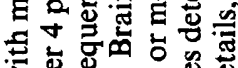

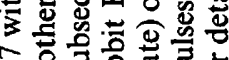

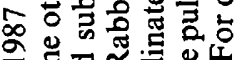
웜

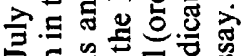

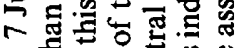
온

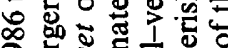

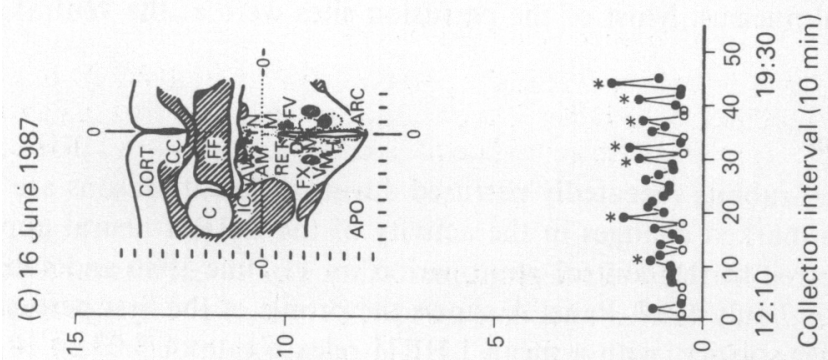

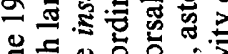

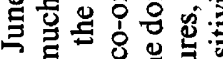
ㅂ.

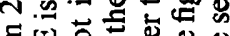

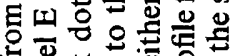

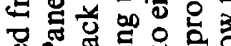

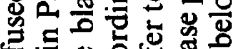
든 워웛ㅇ

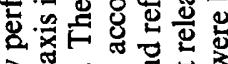
거웡

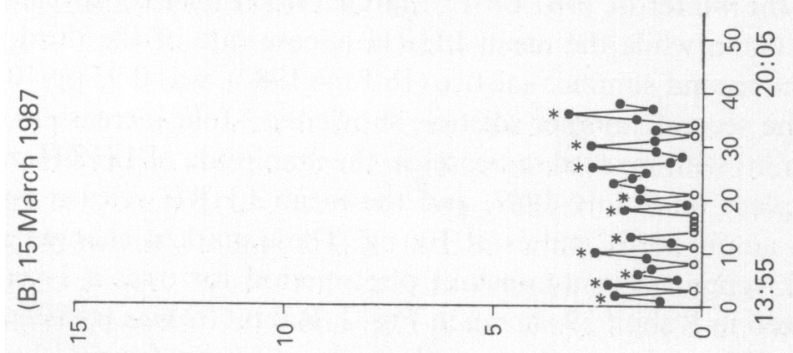

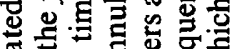

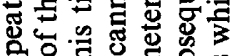
언

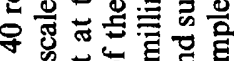

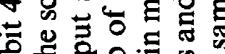

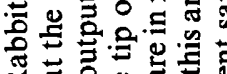

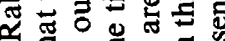

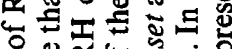

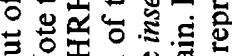

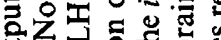

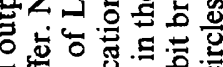

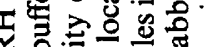

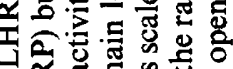
约 至

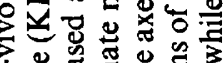

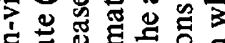

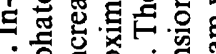
-

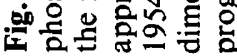

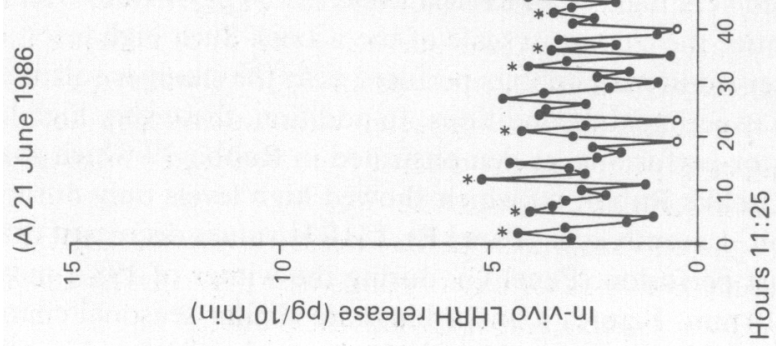


(A) 23 June 1986

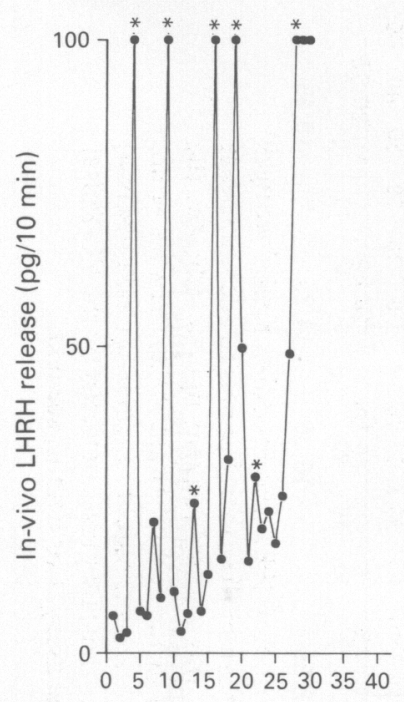

Hours 15:27
(B) 29 July 1986

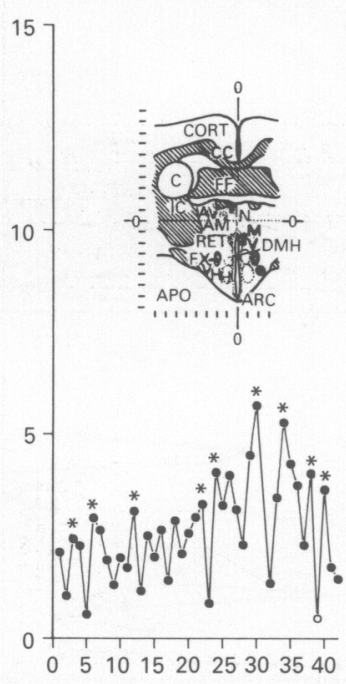

12:35
(C) 13 Feb. 1987

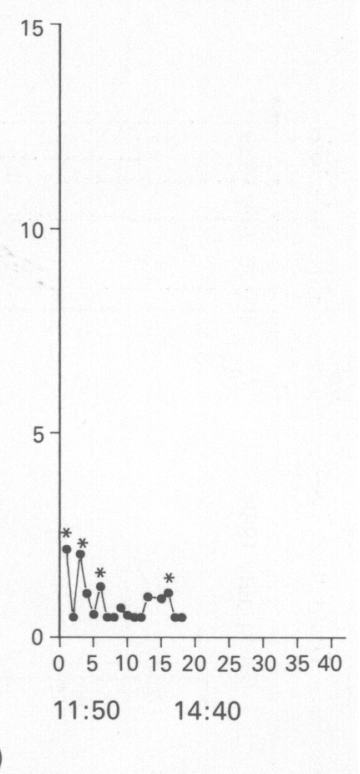

Fig. 2. In-vivo LHRH output of Rabbit 39 repeatedly perfused on 23 June 1986, 29 July 1986 and 13 February 1987 with modified KRP buffer. Note that the scale of the $y$ axis in Panel A is much larger than in the other 2 panels to accommodate the increased activity of LHRH output at this time.

showed less dramatic changes in LHRH release rates, probably due to the cannula placements which were more anterior and/or ventral than in the other animals. In Rabbit 137, mean LHRH concentrations peaked on 11 July 1989, followed by a $50 \%$ decrease on 20 July 1989 . Rabbit 138 was perfused near the summer and the winter solstice and mean LHRH values also peaked on 10 July, followed by a decrease in November, and reached minimal levels 2 days before the winter solstice (19 December 1989).

To summarize and analyse our results statistically, perfusion experiments were grouped into Periods A-F (see 'Materials and Methods'). The effects of seasonal changes on the function of the LHRH neural apparatus were analysed by obtaining the maximal and minimal values of mean release, mean amplitude and mean frequency from the data of every animal in each block. These data (mean \pm s.e.m.) are shown in Fig. 5. The $\mathrm{N}$ represents the number of rabbits in each block. Maximal and minimal values were obtained from 6, 10,9, 23, 7 and 4 perfusions corresponding to the A, B, C, D, E and F blocks, respectively. During the summer solstice, 6 of the animals were perfused once while another 5 were perfused 2-3 times since during this period we observed rather abrupt changes in LHRH activity. The twelfth rabbit (Rabbit 40) was perfused 5 times over 2 consecutive summer solstice periods. A Kruskal-Wallis one-way analysis of variance followed by the Mann-Whitney $U$ test were performed on these data, and an $\alpha \leqslant 0.05$ was required for results to be considered statistically significant. In addition, the mean release, mean amplitude and mean frequency of LHRH pulses during each perfusion experiment were analysed similarly, but in this case the total number of perfusions in each block were used.

In Group D (summer solstice), the maximal mean LHRH release levels and LHRH amplitude (mean \pm s.e.m.) were increased compared with all other groups (see Fig. 5). The maximal mean LHRH pulse frequency in Group D was higher than in Groups A, C and F.

During the winter solstice period (Group A), minimal LHRH release levels were lower than in all other groups (see Fig. 5). Maximal LHRH amplitude values during the winter solstice period 

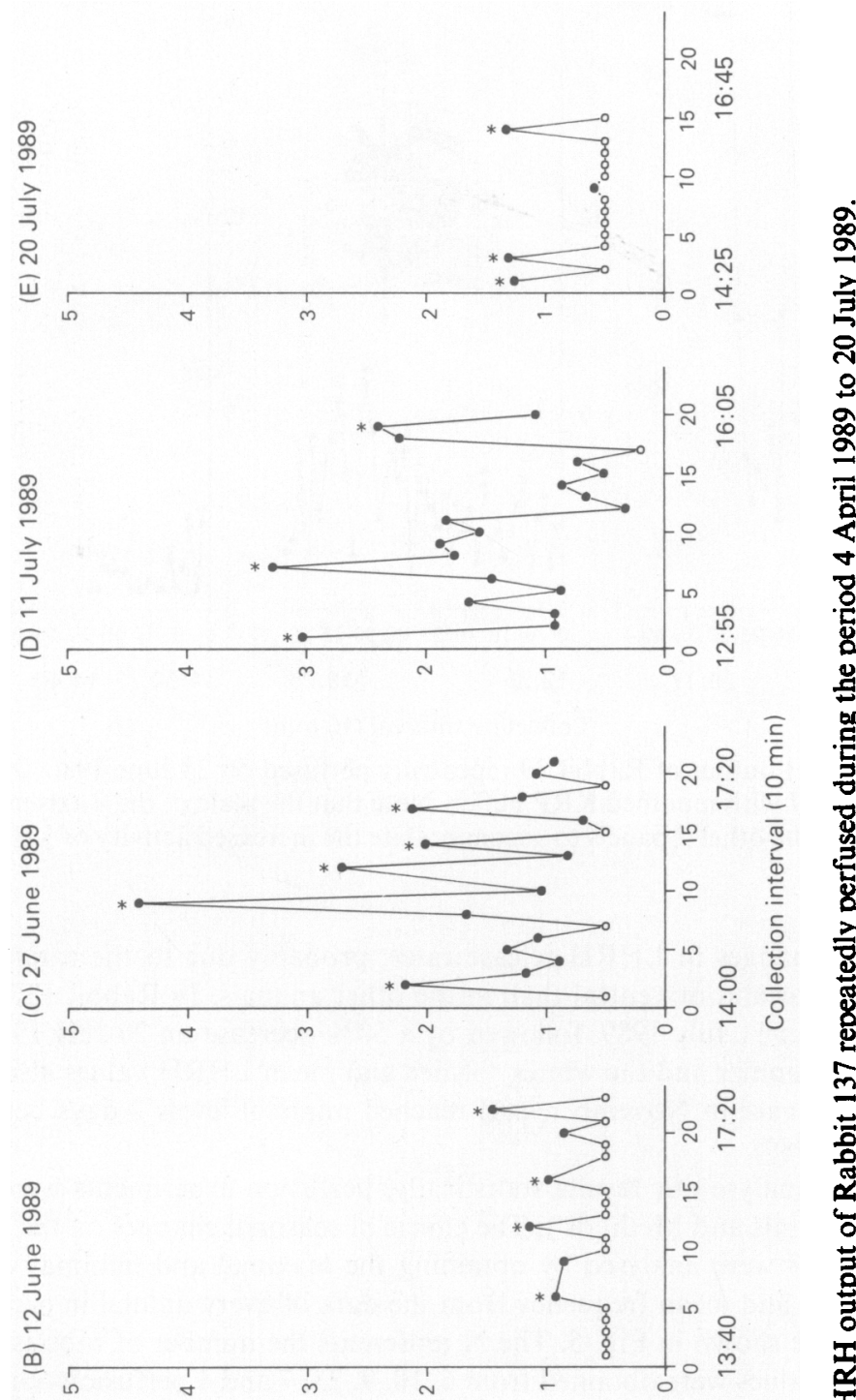

年

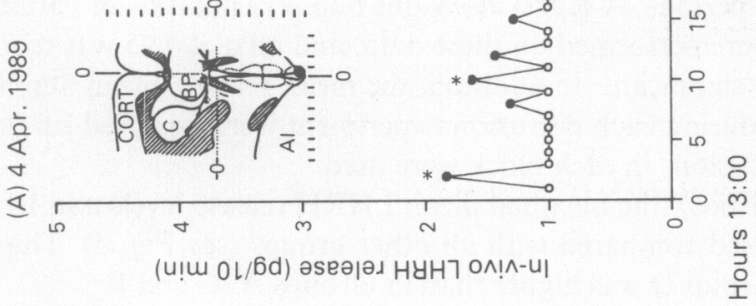

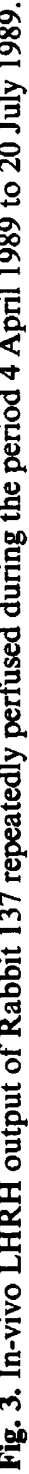



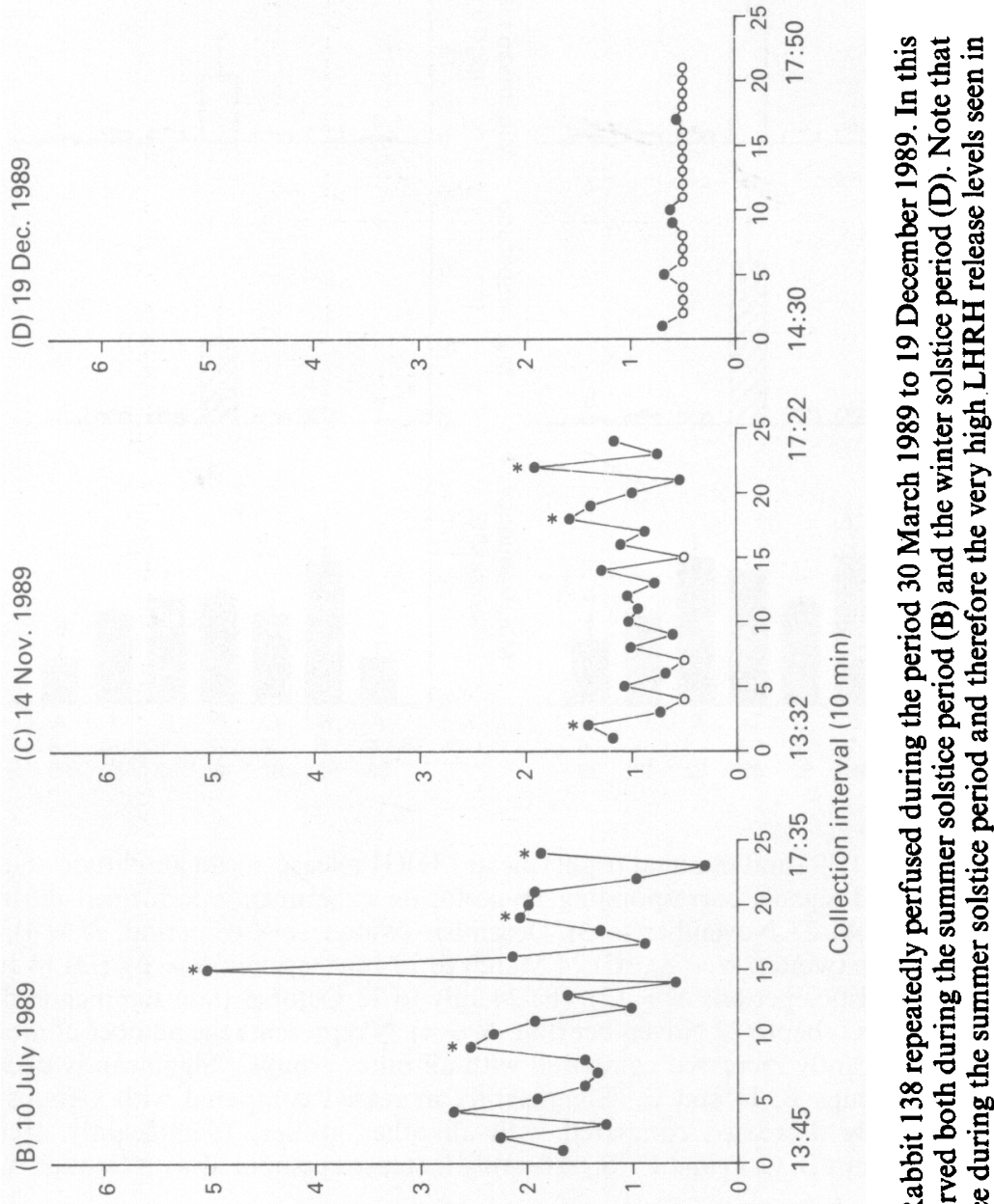

के फ़्क

․ㅡㄹ

总

记

ठृิ

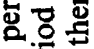

焉焉

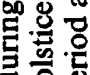

ช⿺辶

空

\&.

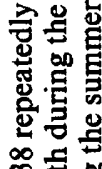

象运造。

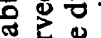

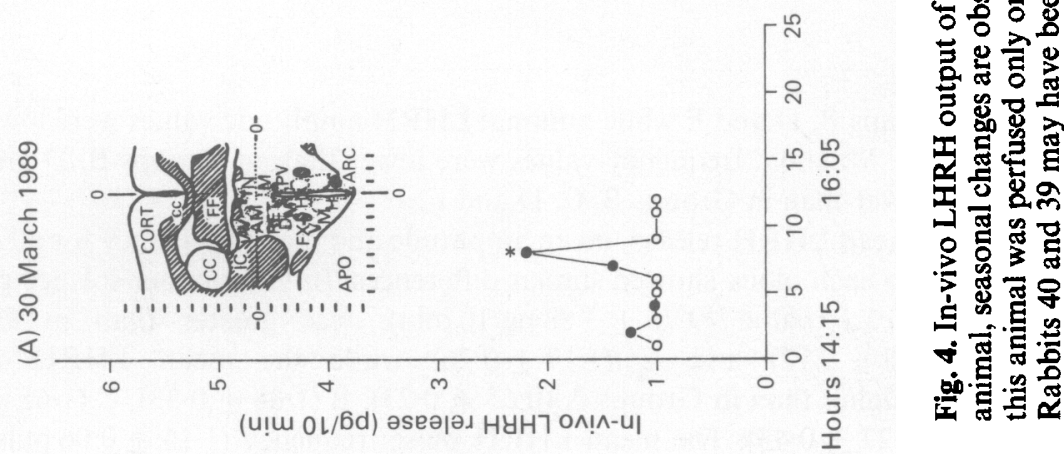



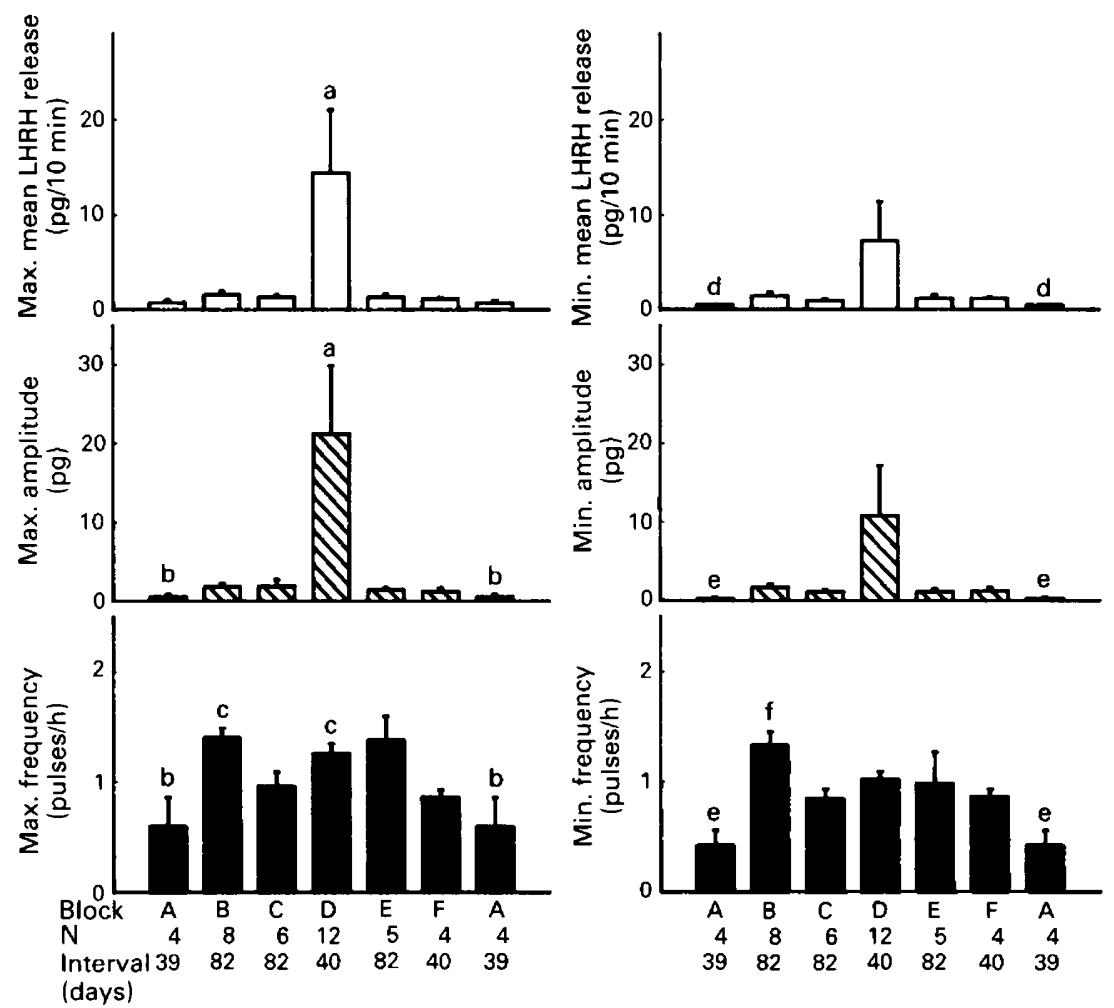

Fig. 5. The maximal (left) and minimal (right) mean LHRH release, mean amplitude and mean frequency of LHRH signals corresponding to perfusion experiments performed during the following periods: (A) 23 November to 31 December (winter solstice period: $N=4$ ), (B) 1 January to 23 March (winter: $N=8$ ), (C) 24 March to 13 June (spring: $N=6$ ), (D) 14 June to 23 July (summer solstice period: $N=12$ ), (E) 24 July to 13 October (late summer-early fall: $N=5$ ) and (F) 14 October to 22 November (fall: $N=4$ ). $N$ represents the number of rabbits in each block. "Significantly increased compared with all other groups. 'Significantly decreased compared with Groups B, D and E. 'Significantly increased compared with Groups A, C and F. 'Significantly decreased compared with all other groups. ${ }^{\text {eSignificantly decreased }}$ compared with Groups B, C, D and F. 'Significantly increased compared with Groups A, C, D and $\mathrm{F}$.

were lower than in Groups B, D and E while minimal LHRH amplitude values were lower than in Groups B, C, D and F. Maximal frequency values were lower than in Groups B, D and E while minimal values were lower than in Groups B, C, D and F.

An analysis of the mean LHRH release, mean amplitude and mean frequency for all the experiments corresponding to each block showed similar differences. In the summer solstice group (D), the mean LHRH release value $(9.76 \pm 3.88 \mathrm{pg} / 10 \mathrm{~min})$, was greater than in Groups A $(0.78 \pm 0.20), C(1.20 \pm 0.17)$ and $E(1.17 \pm 0.26)$ while the mean LHRH amplitude $(13.82 \pm 5.10 \mathrm{pg})$ was higher than in Groups A (0.65 \pm 0.23$), \mathrm{B}(1.64 \pm 0.33), \mathrm{C}(1.65 \pm 0.56), \mathrm{E}$ $(1 \cdot 16 \pm 0.27)$ and $F(1.27 \pm 0.43)$. The mean LHRH pulse frequency $(1 \cdot 16 \pm 0.06 \mathrm{pulses} / \mathrm{h})$ was higher than in Groups A $(0.69 \pm 0.19), C(0.96 \pm 0.09)$ and $F(0.86 \pm 0.07)$. In the winter solstice group (A), mean LHRH release levels and mean LHRH amplitude were decreased compared with Groups B, C and D. Mean frequency values were lower $(0.69 \pm 0.19$ pulses $/ \mathrm{h})$ than in Groups B $(1 \cdot 30 \pm 0 \cdot 10)$ and $D(1 \cdot 16 \pm 0.06)$. 


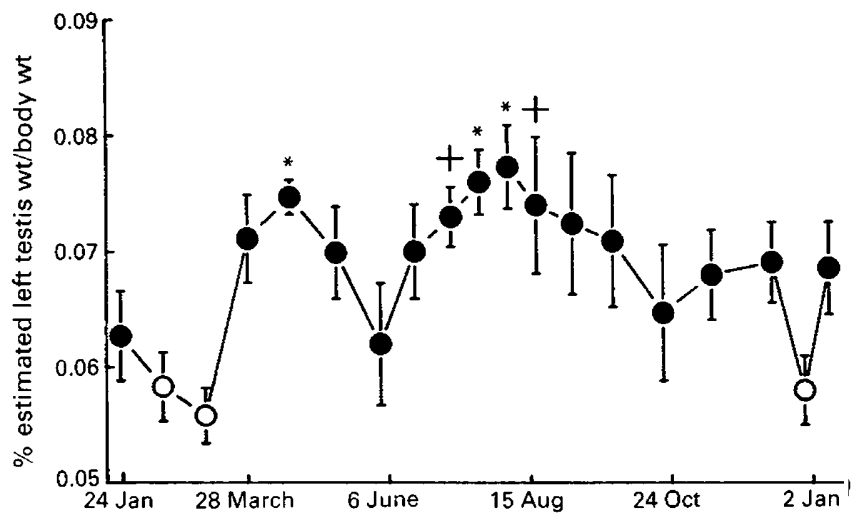

Fig. 6. The mean percentage estimated left testis weight/body weight was measured every 2-5 weeks in male rabbits $(\mathrm{N}=4-7)$ from 24 January 1989 to 10 January 1990 . These data were analysed using one-way analysis of variance followed by the least significance difference test. ${ }^{*} P<0.05$ compared with measurements taken on 14 February, 7 March and 29 December (open circles). $\uparrow P<0.05$ compared with measurements taken on 7 March (second open circle).

The maximal (see Fig. 5) and mean LHRH pulse frequency values during the period immediately after the winter solstice (Group B) were higher than in Groups A, C and F while the minimal pulse frequency value in Group B was higher than in Groups A, C, D and F.

The measurements of testicular weight (Fig. 6) show that the $\%$ testis weight/body weight peaked in early August, similar to the time at which LHRH release values peaked, and reached minimal levels during the winter months in agreement with published data (Boyd, 1985, 1986b). In addition, there was a significant increase in March with values decreasing slightly before the greater and broader increase during the period 7 July to 18 August.

\section{Discussion}

To our knowledge, the present study provides one of the first reports of using a push-pull cannula in an attempt to measure seasonal changes in the same animal with repeated perfusions over an extended period of time up to 1 year in length. This report shows some of the technical assets of the push-pull cannula procedure through the ability to perfuse an animal 5 times or more over a period of 1 year. This technique therefore can be used as a very effective and unique tool in the rabbit to examine circannual cues on the activity of a specific neuronal system, such as the LHRH system. This study reveals several interesting characteristics regarding the seasonal changes of the LHRH neural apparatus in the male New Zealand White rabbit. First, there is a marked increase in LHRH release during and within 1 month after the summer solstice (14 June to 23 July). These changes correspond to high values of percentage estimated testicular weight which peak in early August. Second, there is a marked decrease in the activity of the LHRH neural apparatus during the winter solstice period (23 November to 31 December) which is associated with decreases in percentage estimated testis weight. Third, there is a significant increase in the frequency of LHRH pulses which was observed after the winter solstice (1 January to $23 \mathrm{March}$ ). Finally, the seasonal changes in the LHRH neural apparatus are observed even after the rabbits were transferred from natural lighting and temperature conditions to a controlled light and temperature environment for, in some cases, $>1$ year.

The marked increase in the activity of the LHRH neural apparatus during the period 14 June to 23 July was seen in the mean LHRH release and amplitude of LHRH pulses. This was associated with increases in testicular size found in this study as well as by Boyd (1985) and with peak values of testosterone, LH and testis weight (Lincoln, 1976). In addition, the pituitary response of LH to 
intravenous injections of LHRH is the highest during the months of July and August (Caillol et al., 1989). It is possible that increases in testosterone concentrations may increase the biosynthesis as well as the release of LHRH through long-lasting effects, as has been convincingly shown in the male rat (for review, see Kalra \& Kalra, 1989; Rothfeld et al., 1987; Park et al., 1988; Wiemann \& Steiner, 1989). In the present study, LHRH release levels and testicular weights were still increasing in the month after the summer solstice. One explanation could be because there was a shift in the seasonal pattern in the rabbits now housed indoors. Another explanation for these findings may be because the inhibiting influence of the summer solstice is not immediate, but gradual, such as with its effect on testicular regression. In addition, in the present study, a slight increase in percentage estimated testicular size was seen during the early spring which coincides with the beginning of the period of peak fecundity in wild rabbits (Boyd \& Myhill, 1987).

There was a marked decrease in the activity of the LHRH neural apparatus during the winter solstice period (23 November to 31 December) which was also associated with decreases in percentage estimated testis weight. The present data support a study by Boyd (1985, 1986b), which has shown that after the summer solstice, testicular regression occurs in August and continues into the winter months. In addition, after the summer solstice, there is an increase in size of the pineal gland which is inversely related to the weight of the testis and plasma and testicular testosterone concentrations (Lincoln, 1976). This suggests a role for melatonin in these seasonal changes.

The marked increase in the frequency of the LHRH neural apparatus during the period 1 January to 23 March compared with several of the other blocks may be explained by a rebound effect after the marked decrease in frequency observed during the winter solstice period, which subsequently activates the LHRH neural apparatus after this inhibitory stage. The higher frequency level was maintained through the summer solstice and began to drop during the fall. Mean LHRH release and amplitude were also higher during this rebound period compared with the winter solstice period.

These results also support other findings which have indicated that the male rabbit is a seasonal breeder very sensitive to changes in photoperiod (Boyd, 1986b). There is photoperiodic regulation of sexual activity in the male rabbit as well as changes of testicular weight in response to increases in duration of light (Walter et al., 1968; Boyd, 1986a). These changes have been suggested as being influenced by the pineal gland (Lincoln, 1976) through a signal such as melatonin (Boyd, 1985). The effect of photoperiod on LH and FSH release has been studied in the male rabbit by measuring gonadotrophin secretion in castrated and intact male rabbits exposed to different photoperiods (Boyd, 1987). Plasma LH and FSH concentrations increased after castration during long daylengths, but these levels decreased after rabbits were exposed to short daylengths, suggesting that removal of gonadal steroids does not eliminate the photoperiodic influence in rabbits.

The data of the present report become more intriguing when considering the fact that the seasonal changes in the LHRH neural apparatus and testicular size were observed even after the rabbits were transferred from natural lighting and temperature conditions to a controlled light and temperature environment for, in some cases, $>1$ year. Furthermore, in this study, all the rabbits showed remarkably similar seasonal changes although they were transferred from the natural environment during different seasons (11 in the spring, 2 in the summer, 1 in the fall and 5 in the winter) and remained in the controlled environment for varied periods of time with a minimum of 10 days before the first perfusion. In addition, these marked LHRH increases were observed in a confined period around the summer solstice lasting only 40 days while marked decreases were also observed within a narrow period around the winter solstice lasting only 39 days. Others have also observed seasonal changes in a controlled environment in rabbits when measuring changes in testicular size (Carson \& Amann, 1972). Male rabbits housed for 1-4 months under a constant photoperiod with $13 \mathrm{~h}$ of light and a temperature-controlled environment showed seasonal changes of testicular size (Carson \& Amann, 1972). These observations raise a number of questions regarding the mechanisms by which animals retain seasonal cues when confined to standardized and constant laboratory conditions, as shown in the elegant study of Karsch et al. (1989) with sheep. 
More rigorous studies are required to prove or deny the possibility of an inborn genetic circannual clock controlling seasonal changes in LHRH release.

Further studies will be required to examine the role of seasonal effects on the spontaneous activity of the LHRH neural apparatus. One interesting question is to examine whether or not there are such dramatic seasonal changes of the LHRH neural apparatus in the female New Zealand rabbit since the female rabbit also shows marked seasonal patterns in fecundity, receptivity (Sawyer, 1959) and oestradiol secretion (Batra \& Källstrand, 1979). In addition, previous work in our laboratory suggests that the LHRH neural apparatus has higher activity during the spring and early fall-late summer months (Ramirez et al., 1986). Another interesting question is the role of gonadal steroids on the seasonal changes in LHRH release. The increase in testicular weight during the summer solstice shown in the present data as well as in other laboratories (Lincoln, 1976; Boyd, 1985) suggests that testosterone may be playing an important role in regulating and/or stimulating the increase in LHRH release. On the other hand, Boyd (1987) has found that castration does not have an effect on the photoperiodic effect on LH and FSH release. Obviously, the effect of testosterone on seasonal changes at the level of the hypothalamus needs to be examined more thoroughly.

We thank Dr D. E. Dluzen for reviewing this paper and Mr B. Sylavong for assistance with animal care. This work was supported by an NSF grant DCB-85-09064 to V.D.R. and an NIH training fellowship (grant PHS-5-T32HD07028) (W.W.L.).

\section{References}

Batra, S. \& Källstrand, K. (1979) Are there cyclic variations in estradiol secretion in the non-pregnant rabbit? Experientia 35, 699-701.

Boyd, I.L. (1985) Effect of photoperiod and melatonin on testis development and regression in wild European rabbits (Oryctolagus cuniculus). Biol. Reprod. 33, 21-29.

Boyd, I.L. (1986a) Photoperiodic regulation of seasonal testicular regression in the wild European rabbit (Oryctolagus cuniculus). J. Reprod. Fert. 77, 463-470.

Boyd, I.L. (1986b) Effect of daylength on the breeding season in male rabbits. Mammal Rev. 16, 125-130.

Boyd, I.L. (1987) Gonadotrophin secretion and pituitary responsiveness to LHRH in castrated and intact male rabbits exposed to different photoperiods. J. Reprod. Fert. 79, 627-633.

Boyd, I.L. \& Myhill, D.G. (1987) Seasonal changes in condition, reproduction and fecundity in the wild European rabbit (Oryctolagus cuniculus). J. Zool., Lond. 212, 223-233.

Caillol, M., Meunier, M., Mondain-Monval, M. \& Simon, P. (1989) Seasonal variations in testis size, testosterone and LH basal levels, and pituitary response to luteinizing hormone releasing hormone in the brown hare, Lepus europaeus. Can. J. Zool. 67, 1626-1630.

Carson, W.S. \& Amann, R.P. (1972) The male rabbit. VI. Effects of ejaculation and season on testicular size and function. J. Anim. Sci. 34, 302-309.

Davis, G.J. \& Meyer, R.K. (1973) FSH and LH in the snowshoe hare during the increasing phase of the 10year cycle. Gen. comp. Endocr. 20, 53-60.

Dluzen, D.E. \& Ramirez, V.D. (1986) A miniaturized push-pull cannula for use in conscious, unrestrained animals. Pharmacol. Biochem. Behav. 24, 147-150.

Elder, W.H. \& Finerty, J.C (1943) Gonadotropic activity of the pituitary gland in relation to the seasonal sexual cycle of the cottontail rabbit (Sylvilagus floridanus mearnsi). Anat. Rec. 85, 1-15.

Gitzen, J.F. \& Ramirez, V.D. (1987) PC-Pulsar: pulsar pulse analysis. Psychoneuroendocrinology 12, I-III.

Hartter, D.E. \& Ramirez, V.D. (1985) Responsiveness of immature versus adult male rat hypothalami to dibutyryl cyclic AMP- and forskolin-induced LHRH release in vitro. Neuroendocrinology 40, 476-482.

Kalra, S.P. \& Kalra, P.S. (1989) Do testosterone and estradiol-17 $\beta$ enforce inhibition or stimulation of luteinizing hormone-releasing hormone secretion? Biol. Reprod. 41, 559-570.

Karsch, F.J., Robinson, J.E., Woodfill, C.J.I. \& Brown, M.B. (1989) Circannual cycles of luteinizing hormone and prolactin secretion in ewes during prolonged exposure to a fixed photoperiod: evidence for an endogenous reproductive rhythm. Biol. Reprod. 41, 1034-1046.

Lin, W.W. \& Ramirez, V.D. (1988) Effect of pulsatile infusion of progesterone on the in vivo activity of the luteinizing hormone-releasing hormone neural apparatus of awake unrestrained female and male rabbits. Endocrinology 122, 868-876.

Lin, W.W. \& Ramirez, V.D. (1990) Infusion of progestins into the hypothalamus of female New Zealand White rabbits: effect on in vivo luteinizing hormone-releasing hormone release as determined with push-pull perfusion. Endocrinology 126, 261-272.

Lincoln, G.A. (1976) Seasonal changes in the pineal gland related to the reproductive cycle in the male hare, Lepus europaeus. J. Reprod. Fert. 46, 489-491.

Merriam, G.R.\&Wachter, K.W. (1982) Algorithms for the study of episodic hormone secretion. Am. J. Physiol. 243, E310-E318. 
Park, Y., Park, S.D., Cho, W.K. \& Kim, K. (1988) Testosterone stimulates LH-RH-like mRNA level in the rat hypothalamus. Brain Res. 451, 255-260.

Ramirez, V.D., Ramirez, A.D., Slamet, W. \& Nduka, E. (1986) Functional characteristics of the luteinizing hormone-releasing hormone pulse generator in conscious unrestrained female rabbits: activation by norepinephrine. Endocrinology 118, 2331-2339.

Reed, T.E. (1979) Function of the female reproductive tract. In Domestic Rabbits, Vol. March/April, pp. 8-10. American Rabbit Breeders Association Official Publication, Bloomington, IL.

Rothfeld, J.M., Hejtmancik, J.F., Conn, P.M. \& Pfaff, D.W. (1987) LHRH messenger RNA in neurons in the intact and castrate male rat forebrain, studied by in situ hybridization. Expl Brain. Res. 67, 113-118.
Sawyer, C.H. (1959) Seasonal variation in the incidence of spontaneous ovulation in rabbits following estrogen treatment. Endocrinology 65, 523-525.

Sawyer, C.H., Everett, J.W. \& Green, J.D. (1954) The rabbit diencephalon in stereotaxic coordinates. $J$. comp. Neurol. 101, 801-824.

Walter, M.-R., Martinet, L., Moret, B. \& Thibault, C. (1968) Régulation photopériodique de l'activité sexuelle chez le lapin mâle et femelle. Archs Anat. Histol. Embryol. 51, 773-780.

Wiemann, J.N. \& Steiner, R.A. (1989) Recruitment of neurons expressing gonadotropin-releasing hormone messenger RNA following castration in the adult male rat. Proc. 71 st An. Mtg Endocr. Soc., Seattle, $W A$, Abstr. 930.

Received 9 June 1990 